\title{
Practical Guidelines for the Recognition and Diagnosis of Dementia
}

\author{
James E. Galvin, MD, MPH, and Carl H. Sadowsky, MD
}

To date, user-friendly, practical guidelines for dementia have not been available for busy family physicians. However, the growing number of patients with dementia means that primary care physicians will have an increasingly important role in the diagnosis and subsequent management of dementia. This article provides practical guidance for the recognition and diagnosis of dementia and is aimed at family physicians, who are usually the first clinicians to whom patients present with dementia symptoms. Because Alzheimer disease (AD) is the most common form of dementia, this condition is the main focus of this article. We review the pathophysiology of $\mathrm{AD}$ and discuss recommended diagnostic protocols and the importance of early diagnosis. An AD diagnostic algorithm is provided, with clearly defined steps for screening and diagnosing $\mathrm{AD}$ and assessing daily functioning, behavioral symptoms, and caregiver status. (J Am Board Fam Med 2012;25:367-382.)

Keywords: Dementia, Diagnosis, Diagnostic Techniques and Procedures, Guidelines

\section{Dementia: an Overview}

Alzheimer disease (AD) is the most common form of dementia, accounting for approximately $60 \%$ of all cases, ${ }^{1,2}$ and it is therefore the main focus of this article. AD destroys brain cells, causing problems with memory, thinking, and behavior severe enough to affect work, family, and social relationships and, eventually, the most basic activities of daily living (ADLs). $\mathrm{AD}$ and related disorders are a growing public health problem in the United States, with a prevalence ranging from $3 \%$ to $11 \%$

This article was externally peer reviewed.

Submitted 4 August 2010; revised 17 October 2011; accepted 19 October 2011.

From the Center of Excellence for Brain Aging, New York University Langone School of Medicine, New York, NY (JEG); Division of Neurology, Nova Southeastern University, Fort Lauderdale, FL, and Premiere Research Institute, Palm Beach Neurology, West Palm Beach, FL (CHS).

Funding: none.

Conflict of interest: Dr Sadowsky has served as a consultant to Novartis Pharmaceuticals Corporation, has served as a speaker for Novartis Pharmaceuticals Corporation and Forest Pharmaceuticals and Accera, and has received honoraria from these companies. James E Galvin is a paid consultant for Pfizer, Eisai, Novartis Pharmaceuticals Corporation, Ortho-McNeil and Forest. Neither Dr Sadowsky nor Dr Galvin received financial support for this manuscript.

Corresponding author: James E. Galvin, MD, MPH, Center of Excellence for Brain Aging, New York University Langone School of Medicine, 145 East 32nd Street, 2nd Floor, New York, NY 10016 (E-mail: James.Galvin@nyumc.org). among people aged 65 years and older and from $25 \%$ to $47 \%$ among those aged older than 85 years. $^{3,4}$ There are an estimated 5.3 million cases of dementia in the United States, ${ }^{5}$ and this number is expected to increase to 18.5 million by $2050 .^{6}$ The number of those afflicted is increasing annually as a result of the aging population. Dementia leads to a high burden of suffering for patients, families, and society, with an annual estimated cost of $\$ 172$ billion. ${ }^{5}$

People with dementia usually present first to their family physician, although an estimated 39\% present to specialist clinics (neurologists, psychiatrists and geriatricians). ${ }^{7}$ The primary care physician (PCP) is often the first physician to observe patients with possible dementia and often the only physician involved in making the diagnosis. ${ }^{8} \mathrm{Be}-$ cause of the key role that PCPs play in the longterm management of elderly individuals with chronic disease, the growing number of patients with dementia will have a significant impact on these health professionals. ${ }^{9}$

The rising number of patients with dementia means that family physicians will have an increasingly important role in recognizing early signs and symptoms of disease, ordering appropriate tests, formally diagnosing, and, finally, treating these patients. However, at present, diagnosing $\mathrm{AD}$ can be 
challenging. In the early stages, $\mathrm{AD}$ can be difficult to distinguish from the decline in cognitive abilities due to normal aging and the mild cognitive impairment (MCI) that often precedes AD. ${ }^{10,11}$ Furthermore, there are insufficient numbers of neurologists to care for all the patients with MCI and dementia, and there are a limited number of dementia specialists available for consultation. It is, therefore, imperative that PCPs learn how to assess their patients for dementia; specialty clinics cannot deal with the numbers of patients-a problem that will only worsen as the population continues to age.

To date, user-friendly, practical guidelines have not been available for busy family physicians. Indeed, studies suggest that family physicians may have a relatively limited knowledge of dementia. ${ }^{12,13}$ Thus, there is a pressing need to facilitate diagnosis, which can be simplified by adherence to clearly defined guidelines. This article provides practical guidance for the recognition and diagnosis of dementia and is aimed at PCPs, who are usually the first clinicians to whom patients present with dementia symptoms.

\section{Pathophysiology of AD}

$\mathrm{AD}$ is a progressive neurodegenerative disorder that represents the most common form of dementia. The most prominent clinical feature of $\mathrm{AD}$ is an early impairment of episodic memory, ${ }^{2}$ which manifests as memory impairment of recent events, unusual repeated omissions, and difficulty learning new information. For example, an individual with $\mathrm{AD}$ may ask the same question repeatedly throughout the day, such as what they are going to eat for dinner, or frequently misplace items (glasses, keys, or wallet). The loss of memory, especially for learning and retaining new information, reflects impaired function in the hippocampus and other medial temporal lobe structures, which are sites of early pathologic change. ${ }^{2}$ As the disease progresses, the symptoms often manifest in more persistent language disturbance and difficulties completing more complex tasks of daily living. Patients progress from loss of higher level ADLs, such as the ability to perform financial transactions and drive a car or use public transportation, to abnormalities in the more basic ADLs (eg, personal hygiene, toileting). Behavioral problems frequently develop and include depression, apathy, anxiety, agitation, psychosis (delusions and hallucinations), wandering, and aggression. ${ }^{2}$

\section{Guidelines for Diagnosis}

The diagnosis of $\mathrm{AD}$ is usually based on the $\mathrm{Na}$ tional Institute of Neurological, Communicative Disorders and Stroke-Alzheimer Disease and Related Disorders Association (NINCDS-ADRDA). ${ }^{14}$ According to these guidelines, the diagnosis is classified as definite (clinical diagnosis with histologic confirmation), probable (typical clinical syndrome without histologic confirmation), or possible (atypical clinical features but no alternative diagnosis apparent; no histologic confirmation). The currently accepted criteria support a probabilistic diagnosis of $\mathrm{AD}$ within a clinical context where there is no definitive diagnostic biomarker. A definite diagnosis of $\mathrm{AD}$ is only made according to the NINCDS-ADRDA criteria when there is histopathologic confirmation of the clinical diagnosis. ${ }^{15}$ Autopsy results support the "probable" clinical diagnosis in $86 \%$ to $90 \%$ of cases. ${ }^{16}$

Although the NINCDS-ADRDA criteria for $\mathrm{AD}$ are the prevailing diagnostic standards in research, these have now fallen behind the unprecedented growth in the understanding of the disease process. ${ }^{15}$ The clinical phenotype of $\mathrm{AD}$ is no longer described in exclusionary terms, but it can be characterized more definitively on a phenotypic basis. Distinctive markers of the disease are now recognized, including structural brain changes visible on magnetic resonance imaging with early and extensive involvement of the medial temporal lobe, molecular neuroimaging changes seen with positron emission tomography (PET), and changes in cerebrospinal fluid (CSF) biomarkers. ${ }^{15}$ There recently has been intense research interest in characterizing the earliest stages of disease that predate the crossing of the dementia threshold, defined by functional disability. Prodromal AD is the symptomatic predementia phase of $\mathrm{AD}$, generally included in the MCI category; this phase is characterized by symptoms not severe enough to meet currently accepted diagnostic criteria for $\mathrm{AD} .^{15}$ The presence of at least one biologic footprint of $\mathrm{AD}$ should improve the specificity for diagnosis. This concept forms the foundation of the new diagnostic criteria proposed in 2007 , which were developed to allow an earlier and more specific $\mathrm{AD}$ diagnosis. $^{15}$

The proposed criteria move away from the traditional 2-step approach of first identifying dementia according to degree of functional disability and 
then specifying its cause. ${ }^{15}$ Instead, they aim to define the clinical, biochemical, structural, and metabolic presence of $\mathrm{AD}$ at the earliest stages before full-blown dementia. These new criteria are centered on a clinical core of early and significant episodic memory impairment. They stipulate that there also must be at least one or more abnormal biomarkers among structural neuroimaging with magnetic resonance imaging, molecular neuroimaging with PET, and CSF analysis of $\beta$-amyloid or $\tau$ proteins. ${ }^{15}$ For example, a decrease in the $\beta$-amyloid (1-42) peptide and an increase in the $\tau$ and phospho- $\tau$ proteins may be the earliest signs of AD. ${ }^{2,10,17}$ These criteria represent a cultural shift requiring a more biologically focused workup than previous approaches, and their timeliness is highlighted by the development of drugs that are directed at altering pathogenesis, particularly at the production and clearance of $\beta$-amyloid. ${ }^{2,15}$

Although the focus of research recently has shifted to the development of new tools that increase the specificity of the prodromal $\mathrm{AD}$ diagnosis, ${ }^{2}$ there are no readily available biomarkers, laboratory tests, or brain imaging techniques for routine use to aid diagnosis. ${ }^{18,19}$ As such, their use has limited application for family physicians at this time. Likewise, there are no genetic markers currently recommended for routine use in the diagnosis of $\mathrm{AD}$, including testing for the apolipoprotein $\mathrm{E} 4$ gene or for mutations in amyloid, presenilin, or $\tau$ that have been linked to rare forms of familial dementia. ${ }^{18}$ It therefore remains necessary to screen patients by taking a diligent approach to assessing cognition and function.

\section{Importance and Challenges of Early Diagnosis}

Making a diagnosis of dementia in the early stages can be a clinical challenge. The insidious and variable emergence of dementia symptoms makes recognition of the syndrome problematic, particularly in the primary care setting, ${ }^{20}$ with the often limited time available for consultation. In addition, physicians need to be wary of patients' ability to hide their symptoms. In the early stages of dementia, accommodation to or denial of changes in cognition, functional ability, mood, or behavior are common coping strategies. ${ }^{21}$ As the person's denial strengthens, the concerns of the family become more pressing, with the physician often caught in between and faced with apparently irreconcilable needs. ${ }^{21}$ Most specialty associations, including the
American Academy of Neurology, the American Geriatrics Society, the American Medical Association, and the American Association of Family Practitioners, encourage physicians to be alert to cognitive problems in older adults and to take steps to identify cognitive disorders at the earliest possible stage. However, clinicians in primary care often fail to screen older adults for $\mathrm{AD}$ on a routine basis because of insufficient time, inadequate reimbursement for services, and uncertainty about resources available to facilitate diagnosis. ${ }^{22,23}$ Furthermore, given the wide range of services needed, PCPs often fail to make referrals because of insufficient knowledge about resources. ${ }^{23,24}$

Although it is recognized that current pharmacologic and behavioral interventions do not prevent eventual disease progression, there is good evidence to show that their use can lead to disease stabilization and delayed progression of cognitive, functional, and behavioral outcomes, and these outcomes may provide improvement in quality of life for the patient and their family. ${ }^{22}$ Nevertheless, family physicians should counsel patients with $\mathrm{AD}$ and their families about realistic expectations of treatment outcomes with these agents, which are likely to be modest, ${ }^{25}$ and the potential for mild to moderate adverse effects (mostly nausea, vomiting, diarrhea, or all three). Because damage caused by the pathophysiologic mechanisms associated with $\mathrm{AD}$ is presumed to be irreversible, early detection of $\mathrm{AD}$ offers better prospects for patients with $\mathrm{AD}$ and their families and friends. This allows both the patient and family to participate in their care plan and to prepare better for future challenges as a result of the neurodegenerative process ${ }^{26,27}$ because currently available medications, and any future disease-modifying agents, will have the greatest opportunity for providing benefit. In addition, recent evidence suggests that early treatment provides economic benefits both to the patient and caregiver as well as society as a whole. ${ }^{28-30}$ Hence, the early establishment of a diagnosis and subsequent initiation of an appropriate management program can optimize the prognosis for patients with AD.

Despite the benefits of early intervention, dementia remains underdiagnosed; an estimated 50\% of primary care patients aged older than 65 years have not been diagnosed by their PCPs. A primary reason cited for the delay in $\mathrm{AD}$ diagnosis has been the difficulty in identifying early signs of $\mathrm{AD}$ by 
both PCPs and the general public. ${ }^{31}$ Given the challenges and benefits of timely and accurate diagnosis of neurodegenerative disorders, physicians and patients alike desire tools that aid in dementia diagnosis as early as possible. ${ }^{32}$

\section{AD Diagnosis Algorithm}

Diagnosis of dementia is a stepwise process that involves examination of patient history and early warning signs, as well as performance screening, assessment of daily functioning, behavioral problems, and caregiver status, with possible referral to specialist clinics for more thorough assessment (Table 1).

\section{Step 1: Prediagnostic Tests and Early Warning Signs}

Before any diagnostic tests are performed, patient history, physical examination, and laboratory findings as well as input from family should be considered because these factors are paramount to the diagnosis of dementia (Table 1). ${ }^{33}$ In particular, family physicians should take into account any risk factors for $\mathrm{AD}$ that may be present, including older age, lower education, female sex, and family history of $\mathrm{AD}$ (Table 1).

There are several conditions that mimic dementia (eg, depression, hypothyroidism) that can be missed if not evaluated and, if detected, are potentially reversible. To diagnose $\mathrm{AD}$, other medical, neurologic, or psychiatric disorders that could account for the impairment in memory and related symptoms must be investigated ${ }^{1}$ (Table 1). Furthermore, family physicians need to be aware of the potential for vision and hearing problems that could be contributing in a significant manner to an apparent decline in cognitive function. It also should be noted that patients with $\mathrm{AD}$ frequently have comorbid medical conditions (Table 1), the presence of which can further impair patient function; their appropriate treatment can optimize outcomes and minimize excess disability. ${ }^{12}$ Laboratory tests are necessary to identify or rule out secondary causes of dementia and coexisting disorders that are common among elderly people. ${ }^{1}$ Recommended tests are shown in Table 1.

Even before the onset of cognitive problems, there are several warning signs that can predict those individuals at a higher risk of developing dementia, including increased frequency of patient visits to their family physician before diagnosis. ${ }^{34,35}$ There are also somatic changes that precede the onset of dementia that may provide important clues, including accelerated weight loss, ${ }^{36}$ gait disturbances, physical frailty, ${ }^{37}$ and slowed psychomotor speed ${ }^{36}$ (Table 1).

Ten Key Warning Signs for AD The Alzheimer's Association lists 10 key warning signs of $\mathrm{AD}^{10}$ :

- Memory loss

- Difficulty performing familiar tasks

- Problems with language

- Disorientation to time and place

- Poor or decreased judgment

- Problems with abstract thought

- Misplacing things

- Changes in mood or behavior

- Changes in personality

- Loss of initiative

In many patients, the most clinically prominent feature of $\mathrm{AD}$ is the decline in cognitive function with an early impairment of episodic memory, for example, what the patient cannot recall what they had for breakfast, even with the provision of cues. ${ }^{1}$ Memory complaints are thus the most reliable and easiest to test for signs of early $\mathrm{AD}$.

\section{Step 2: Screening Tools Employed by Family Physicians}

It is crucial that physicians screen for $\mathrm{AD}$ under appropriate conditions with validated screening tools that are suitable for a busy practice. Several screening tools are available for use in primary care and are continually being updated and re-evaluated to provide family physicians with brief, easy to administer, and effective diagnostic tools. All screening tools are readily available to family physicians and can be obtained without incurring costs. Many family physicians may find it helpful to select a few screening tools and become familiar and proficient with them. It should be noted, however, that these screening tools are not specifically diagnostic for AD. Rather, they provide evidence that an impairment exists and a rationale to move to a more formal evaluation for confirmation.

There are 2 basic ways to assess the patient for dementia. One approach is a performance measure in which a test is administered and scored. The score then is compared with a published norm. This method is useful for determining how the patient performs in comparison with other age- 
Table 1. Stepwise Approach to Diagnosing and Assessing Alzheimer Disease in Primary Care

\begin{tabular}{|c|c|c|}
\hline Stage & Purpose & Tools to Use/Information to Obtain \\
\hline
\end{tabular}

Step 1: Prediagnostic tests

Step 2: Assess performance

Step 3: Assess daily functioning

Step 4: Assess behavioral symptoms

Step 5: Identify caregiver and assess needs
Differential diagnosis and determination of coexisting disorders

Cognitive assessments that help screen for/diagnose $\mathrm{AD}$

Determine level of independence and degree of disability

Determine presence and degree of behavioral symptoms

Identify the primary caregiver and assess adequacy of family and other support systems
Risk factors, including age, female sex, apolipoprotein E4 gene, prior head injury, low education, and family history of $\mathrm{AD}$; stroke, obesity, hypertension, hyperlipidemia, hyperhomocysteinemia, diabetes, hyperinsulinemia, and smoking ${ }^{10,65,66}$

Medical history:

- Other ailments that mimic dementia include normal ageassociated memory changes, depression, delirium, drug reactions, vision and hearing problems ${ }^{1}$

Key questions to ask:

- Has the patient had any recent illnesses?

- Has the patient used any new prescription or over-thecounter medications that could cause memory loss, such as benzodiazepines, anticholinergic drugs for urinary incontinence

- Has the patient used or been exposed to illicit drugs?

- Has there been any exposure to environmental toxins, eg, fuels or solvents?

- Has the patient had any head injuries recently?

- Is there any history of epilepsy?

Laboratory/medical tests:

- Complete blood cell count (to ascertain presence of anemia/ infection), glucose and thyroid function tests, serum electrolytes, serum $B_{12}$ levels (to identify vitamin deficiencies), liver function tests, renal function tests, and urinalysis, if appropriate ${ }^{1}$

- Patients with AD frequently have comorbid medical conditions, eg, cardiovascular disease, infection, pulmonary, renal insufficiency, and arthritis. ${ }^{13}$

Early warning signs of preclinical dementia:

- Increased frequency of patient visits to the PCP prior to diagnosis, over a period up to 5 years prior to the diagnosis $^{34,35}$

- Accelerated weight loss, ${ }^{36}$ late-life depression, gait disturbances, and physical frailty ${ }^{37}$

Cognitive tests: ${ }^{*}$

- MMSE ${ }^{12,13}$

- Mini-Cog $39,40,42,67$

- $\mathrm{MoCA}^{68}$

Informant-rated tool:*

- $\mathrm{AD} 8^{63}$

Daily function assessment tool:*

- IADL $^{48,49}$

Behavioral assessment tool:*

- NPI-Q ${ }^{57}$

Assess the patient for drug toxicity and medical psychiatric, psychosocial, or environmental problems that may underlie behavioral changes. ${ }^{13}$

Identify primary carers and establish collaboration:

- Family caregivers are central to the PCP's assessment and care of the patient. ${ }^{59}$

- Establish and maintain collaboration with caregivers. ${ }^{59,60}$

- Routinely incorporate caregivers' reports of patients' changes in daily routine, mood, behavior, and sleeping patterns.

Assess health of primary caregiver:

- Regularly monitor the physical and emotional health of the primary caregiver as well as that of the patient. ${ }^{13}$

- The PCP should assess the caregiver themselves or refer them to a psychologist, social worker, or other member of the health care delivery team. 
Table 1. Continued

\begin{tabular}{|c|c|c|}
\hline Stage & Purpose & Tools to Use/Information to Obtain \\
\hline Special considerations & $\begin{array}{l}\text { Identify culture, language, and } \\
\text { literacy of patient and } \\
\text { caregiver }\end{array}$ & $\begin{array}{l}\text { Culture: } \\
\text { - Recognize the caregiving patterns of ethnic minority groups, } \\
\text { eg, African American and Hispanic families distribute care } \\
\text { among several family members, rather than one primary } \\
\text { carer. } \\
\text { - Ethnic minority groups may place different interpretations } \\
\text { on memory and behavioral problems. } \\
\text { Language: } \\
\text { - Be aware of the preferred language of the patient and } \\
\text { family. } \\
\text { Literacy: } \\
\text { - Recognize that paper-and-pencil tests and forms may not } \\
\text { work well with diverse patient populations if basic literacy is } \\
\text { not present, even when such forms are in the person's native } \\
\text { language. } \\
\text { - Some experts suggest that patients be tested only on what } \\
\text { they reasonably may be expected to know, }{ }^{70} \text { eg, a person } \\
\text { with little schooling may not know how to do the serial } \\
\text { sevens on the MMSE, but may be competent at applying } \\
\text { simple math, such as subtraction, when handling monetary } \\
\text { transactions. }\end{array}$ \\
\hline
\end{tabular}

The initial assessment of cognitive and functional abilities is important to determine a baseline to which future deficits may be compared. Reassessment of the patient every 6 months is recommended, and more often in cases of sudden changes in behavior or increased rate of decline. ${ }^{13}$

${ }^{*}$ Refer to Table 2 for further details.

$\mathrm{AD}$, Alzheimer disease; AD8, 8-item Ascertain Dementia tool; IADL, instrumental (or intermediate) activities of daily living; MMSE, Mini-Mental State Examination; Mini-Cog, Mini Cognitive Assessment Instrument; MoCA, Montreal Cognitive Assessment; NPI-Q, Neuropsychiatric Inventory Questionnaire; PCP, primary care physician.

matched individuals, and scores can be followed over time; however, unless previous baseline testing was performed, the score is not able to give the clinician information about whether the patient's cognitive abilities have changed, nor whether the impairment interferes with everyday activities. In addition, brief performance measures may be biased by age, race, sex, education, and socioeconomic status. A second approach is an informant interview. An observant informant can provide information about how the patient's cognitive abilities have changed and whether the change interferes with everyday activities. Because each patient serves as his or her own control, these assessments suffer less from biases. However, the limitation may be in finding an informant for older adults who live by themselves or in skilled nursing facilities. A combination approach with an informant and performance measure may improve the ability to detect dementia at the earliest stages. ${ }^{38}$

\section{Performance-Based Screening Tools}

In terms of assessing cognitive function, the MiniMental State Examination (MMSE) test has been used frequently for initial assessment of $\mathrm{AD}$, and its sensitivity increases if a decline of the score over time is taken into account ${ }^{7,17}$ (Table 2). Although the MMSE is quick and easy to administer and can track the overall progression of cognitive decline, it is not considered to be a good test for definitive $\mathrm{AD}$ diagnosis. ${ }^{1}$ In addition, there are several issues associated with the MMSE, including bias according to age, race, education, and socioeconomic status (Table 2). ${ }^{39}$

Several screening tools are now available for use in primary care as alternatives to the $\mathrm{MMSE}^{7,17}$; these are being updated continually to provide PCPs with brief, easy to administer, and effective diagnostic tools. The Mini-Cognitive Assessment Instrument (Mini-Cog) has sensitivity and specificity for dementia similar to that of the MMSE (Table 2). ${ }^{40}$ However, the Mini-Cog's brevity may be an advantage when trying to improve recognition of cognitive impairment in primary care. ${ }^{40,41}$ In addition, the Mini-Cog is not associated with the same language or education bias as the MMSE. ${ }^{39,42}$ An example of the Mini-Cog test is provided in Appendix 1.

Newer instruments, such as the Montreal Cognitive Assessment, a screening tool developed to 


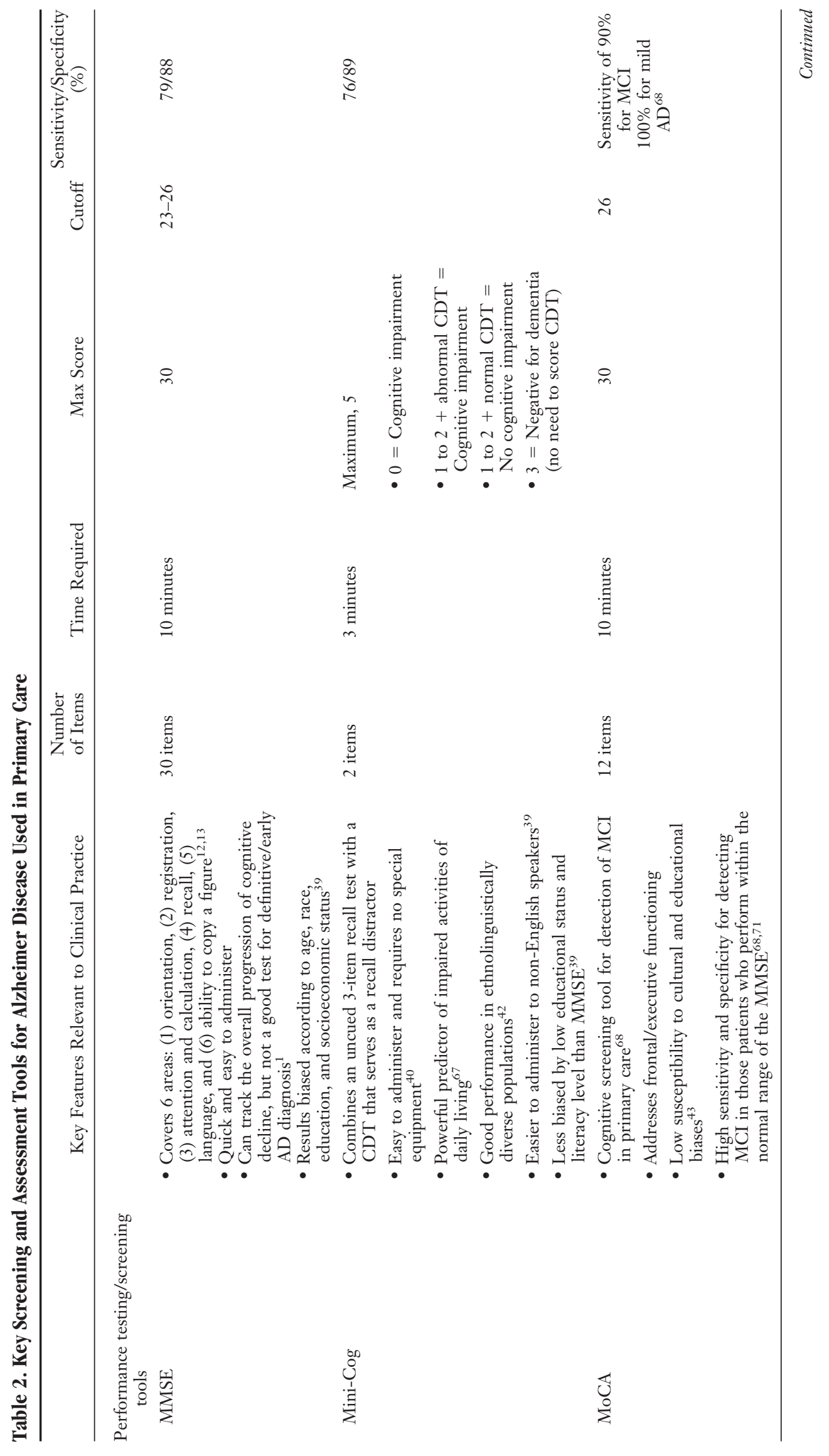




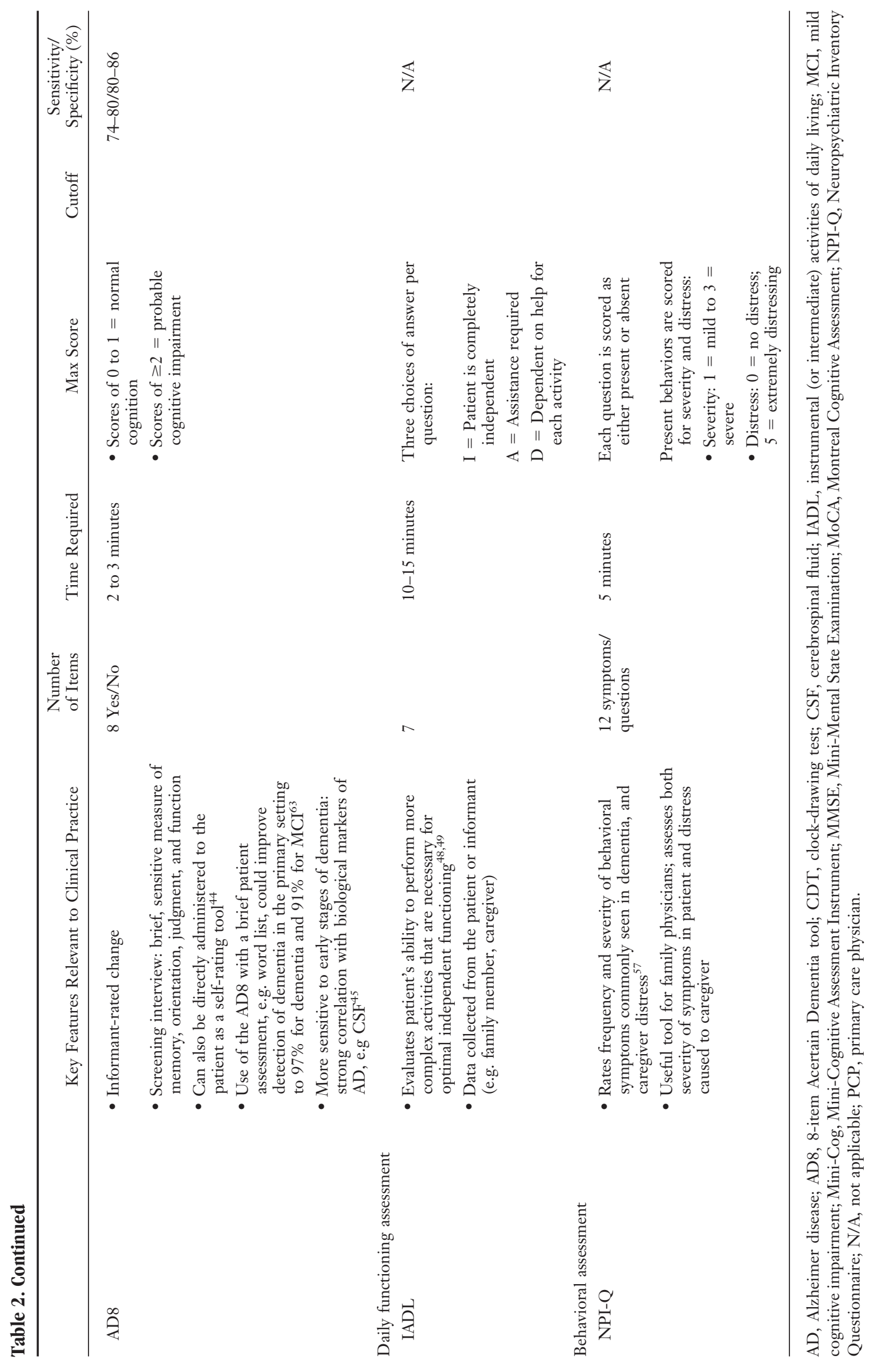

羡

. 
assist PCPs in detecting MCI, are gaining credibility because of improvements in sensitivity and decreasing susceptibility to cultural and educational biases (Table 2). ${ }^{43}$ Although more complex than the MMSE and Mini-Cog, the Montreal Cognitive Assessment offers the advantage of testing multiple cognitive domains with an easy scoring system and is free for clinical use (www.mocatest.org). There are many other short and simple memory tests available that can be used as first-line screening tools for use in primary care. ${ }^{17}$ Each has its pros and cons; the important point is that an objective measurement can provide an accurate "snapshot" of the patient's cognitive abilities and permits a quantitative measurement to follow for evidence of a treatment response.

\section{Informant-Based Screening Tools}

Another key test used in primary care is the 8-item Ascertain Dementia (AD8) screening interview, which is a brief, sensitive measure that reliably differentiates between individuals with and without dementia by querying memory, orientation, judgment, and function (Table 2). The AD8 can be completed by the informant in the waiting room before the office visit. In the absence of an informant, the AD8 also can be completed by the patient as a self-rating tool. ${ }^{44}$ Because the diagnosis of dementia requires a cognitive deficit that represents a change from premorbid abilities and interferes with social and occupational functioning, an informant assessment provides information that a performance measure cannot. Informant interviews such as the AD8 may be more sensitive to early stages of dementia and have strong correlation with biological markers of $\mathrm{AD}$ such as CSF and PET studies. ${ }^{45}$ An example of the AD8 test is provided in Appendix 2.

Of the tests described above, the Mini-Cog and AD8 are recommended as key diagnostic tools to use in primary care because they are brief, valid, and reliable instruments that are easy to administer, clinically acceptable, and effective. Both have psychometric properties superior to the MMSE; as such, they are clinically and psychometrically robust and, it has been argued, are more appropriate for routine use in primary care..$^{27,46}$

\section{Step 3: Assessment of Daily Functioning}

An assessment of daily function is vital to determine the extent of the patient's disability and de- pendence on the caregiver, the results of which help to enable planning to maximize patients' independence. ${ }^{47}$ Basic ADLs, such as feeding and toileting, can be assessed with an interview or by using a tool such as the ADL Scale. Assessment of instrumental ADLs (IADLs) addresses more advanced activities, such as shopping, cooking, and managing finances. The IADL scale is used most frequently and measures 7 areas of more complex activities required for optimal independent functioning ${ }^{48,49}$ (Table 2; Appendix 3). The cognitive changes commonly associated with $\mathrm{AD}$ first impact the instrumental and, eventually, the basic ADLs. ${ }^{50-52}$ Another commonly used scale is the Functional Assessment Questionnaire (FAQ), ${ }^{53}$ which includes 10 items and has been developed from the IADL scale. It assesses shopping, handling finances, preparing a meal, and traveling (which are also in the IADL scale); remembering appointments; and paying attention to, understanding, and discussing television, a book, or a magazine. The total score ranges from 0 (independent) to 30 (dependent). ${ }^{53}$ An example of the FAQ is provided in Appendix 4.

\section{Step 4: Assessment of Bebavioral Symptoms, Psychotic Symptoms, and Depression}

More than $80 \%$ of patients with $\mathrm{AD}$ experience some form of behavioral symptoms such as anxiety, agitation, depression, and apathy during the course of the disease, ${ }^{54-56}$ and patients should, therefore, be assessed periodically. Although these symptoms may be observed by the family physician, they are more often reported by the primary caregiver. ${ }^{13}$

Standardized tools can be used by PCPs or clinic staff to gather information about behavioral symptoms from the caregiver and evaluate effectiveness of interventions over time. The Neuropsychiatric Inventory Questionnaire is a quickly administered instrument that provides reliable assessment of behaviors commonly observed in patients with dementia $^{57}$ (Table 2; Appendix 5). In addition, the Behavioral Pathology in Alzheimer's Disease (BEHAVE-AD) Rating Scale was designed particularly to be useful in prospective studies of behavioral symptoms and in pharmacologic trials to document behavioral symptoms in patients with $\mathrm{AD} .{ }^{58}$ The BEHAVE-AD Rating Scale has 2 parts: the first concentrates on symptomatology and the second requires a global rating of the symptoms on a 4-point scale of severity. The domains covered are paranoid and delusional ideation, hallucinations, 
activity disturbances, aggression, diurnal variation, mood and anxieties, and phobias. ${ }^{58}$

\section{Step 5: Caregiver Needs and Status/Support system}

Family caregivers are central to the PCP's assessment and care of the patient with $\mathrm{AD},{ }^{59}$ and establishing and maintaining collaboration with caregivers is critical for care of the AD patient. ${ }^{59,60}$ Indeed, major physician organizations, such as the American Academy of Neurology ${ }^{61}$ and the American Association for Geriatric Psychiatry, ${ }^{62}$ have emphasized the importance of family caregivers by encouraging family physicians to form partnerships with families who care for dementia patients (Table 1).

In addition, the physical and emotional health of the primary caregiver is crucial in obtaining optimal care for the $\mathrm{AD}$ patient. Caregivers suffer from increased rates of depression and physical illness, ${ }^{13}$ and family physicians need to monitor regularly the health of the primary caregiver as well as that of the patient with $\mathrm{AD}$ (Table 1). Assessing caregiver status can lead to the implementation of measures that minimize patient-caregiver stress and delay institutionalization of the patient.

\section{Additional Considerations}

The family physician should be aware of the need for cultural, language, and literacy assessment within the clinical evaluation process for $\mathrm{AD}$. Identifying the patient's and family's culture, values, primary language, literacy level, and decision-making processes will enable optimal assessment and management of $\mathrm{AD}$ patients and their families ( $\mathrm{Ta}$ ble 1).

\section{Referral: Role of the Specialist and Further Investigations}

Difficulty making a diagnosis may necessitate referral to a specialist, such as a geriatrician, neurologist, or psychiatrist, or require the request for further investigations to be completed by a neuropsychologist. For those with mild or questionable impairment, more comprehensive standardized cognitive assessments can be useful to assist with establishing a firm diagnosis; these are normally undertaken as part of a specialist assessment after referral. $^{7}$

\section{Conclusion}

The growing number of patients with dementia means that PCPs will have an increasingly impor- tant role in the diagnosis and subsequent management of disease. There has been unprecedented growth of scientific knowledge about $\mathrm{AD}$ and a subsequent move toward its earlier diagnosis. However, in the absence of biomarkers and brain imaging that can be used routinely in primary care, the emphasis remains on the family physician's ability to recognize and diagnose $\mathrm{AD}$ using performance screening tools. Of the newly available screening tools for use by PCPs, the Mini-Cog and AD8 are particularly useful as complementary, brief, easy to administer, and effective diagnostic assessments that can be used in everyday clinical practice. Alongside cognitive and daily functioning assessments, a thorough evaluation of behavioral symptoms and caregiver status is required to ensure that both the patient and the patient's family receive optimal care.

The authors would like to thank Frances Gambling for her editorial assistance with the manuscript. Administrative, editorial, and technical assistance was funded by Novartis Pharmaceuticals Corporation.

\section{References}

1. deSouza L, Sarazin M, Goetz C, Dubois B. Clinical investigations in primary care. Front Neurol Neurosci 2009;24:1-11.

2. Dubois B, Picard G, Sarazin M. Early detection of Alzheimer's disease: new diagnostic criteria. Dialogues Clin Neurosci 2009;11:135-9.

3. Boustani M, Callahan CM, Unverzagt FW, et al. Implementing a screening and diagnosis program for dementia in primary care. J Gen Intern Med 2005; 20:572-7.

4. Boustani M, Peterson B, Hanson L, Harris R, Lohr $\mathrm{KN}$. Screening for dementia in primary care: a summary of the evidence for the U.S. Preventive Services Task Force. Ann Intern Med 2003;138:927-37.

5. Alzheimer's Association. 2010 Alzheimer disease facts and figures. Alzheimer's \& Dementia. Vol. 6. Available from: http://www.alz.org/documents_ custom/report_alzfactsfigures2010.pdf. Accessed 14 March 2012.

6. Sloane PD, Zimmerman S, Suchindran C, et al. The public health impact of Alzheimer's disease, 20002050: potential implication of treatment advances. Annu Rev Public Health 2002;23:213-31.

7. National Institutes of Health and Clinical Excellence. Dementia: supporting people with dementia and their carers in health and social care. Available from: http://www.nice.org.uk/guidance/cg42. Accessed 27 March 2012.

8. van Hout HP, Vernooij-Dassen MJ, Stalman WA. Diagnosing dementia with confidence by GPs. Fam Pract 2007;24:616-21. 
9. Langa KM, Chernew ME, Kabeto MU, et al. National estimates of the quantity and cost of informal caregiving for the elderly with dementia. J Gen Intern Med 2001;16:770-8.

10. Salloway S, Correia S. Alzheimer disease: time to improve its diagnosis and treatment. Cleve Clin J Med 2009;76:49-58.

11. Morris JC, Storandt M, Miller JP, et al. Mild cognitive impairment represents early-stage Alzheimer disease. Arch Neurol 2001;58:397-405.

12. Cummings JL, Frank JC, Cherry D, et al. Guidelines for managing Alzheimer's disease: part II. Treatment. Am Fam Physician 2002;65:2525-34.

13. Cummings JL, Frank JC, Cherry D, et al. Guidelines for managing Alzheimer's disease: part I. Assessment. Am Fam Physician 2002;65:2263-72.

14. McKhann G, Drachman D, Folstein M, Katzman R, Price D, Stadlan EM. Clinical diagnosis of Alzheimer's disease: report of the NINCDS-ADRDA Work Group under the auspices of Department of Health and Human Services Task Force on Alzheimer's Disease. Neurology 1984;34:939-44.

15. Dubois B, Feldman HH, Jacova C, et al. Research criteria for the diagnosis of Alzheimer's disease: revising the NINCDS-ADRDA criteria. Lancet Neurol 2007;6:734-46.

16. Galasko D, Hansen LA, Katzman R, et al. Clinicalneuropathological correlations in Alzheimer's disease and related dementias. Arch Neurol 1994;51: 888-95.

17. Waldemar G, Dubois B, Emre M, et al. Recommendations for the diagnosis and management of Alzheimer's disease and other disorders associated with dementia: EFNS guideline. Eur J Neurol 2007;14: e1-26.

18. Knopman DS, DeKosky ST, Cummings JL, et al. Practice parameter: diagnosis of dementia (an evidence-based review). Report of the Quality Standards Subcommittee of the American Academy of Neurology. Neurology 2001;56:1143-53.

19. Hye A, Lynham S, Thambisetty M, et al. Proteomebased plasma biomarkers for Alzheimer's disease. Brain 2006;129:3042-50.

20. Iliffe S, Robinson L, Brayne C, et al. Primary care and dementia: 1. diagnosis, screening and disclosure. Int J Geriatr Psychiatry 2009;24:895-901.

21. Woods RT, Moniz-Cook E, Iliffe S, et al. Dementia: issues in early recognition and intervention in primary care. J R Soc Med 2003;96:320-4.

22. Cotter VT. Alzheimer's disease: issues and challenges in primary care. Nurs Clin North Am 2006; 41:83-93, vi.

23. Hinton L, Franz CE, Reddy G, Flores Y, Kravitz RL, Barker JC. Practice constraints, behavioral problems, and dementia care: primary care physicians' perspectives. J Gen Intern Med 2007;22:1487-92.

24. Reuben DB, Roth C, Kamberg C, Wenger NS. Restructuring primary care practices to manage ge- riatric syndromes: the ACOVE-2 intervention. J Am Geriatr Soc 2003;51:1787-93.

25. Kaduszkiewicz H, Zimmermann T, Beck-Bornholdt $\mathrm{HP}$, van den Bussche H. Cholinesterase inhibitors for patients with Alzheimer's disease: systematic review of randomised clinical trials. BMJ 2005;331: 321-7.

26. Vestegaard M, Kerman K, Tamiya E. The study of Alzheimer's disease biomarkers: current role and future prospects of nanosensor technology. Nanobiotechnology 2006;2:5-16.

27. Milne A, Culverwell A, Guss R, Tuppen J, Whelton R. Screening for dementia in primary care: a review of the use, efficacy and quality of measures. Int Psychogeriatr 2008;20:911-26.

28. Winblad B, Wimo A. Assessing the societal impact of acetylcholinesterase inhibitor therapies. Alzheimer Dis Assoc Disord 1999;13(Suppl 2):S9-19.

29. Wimo A. Cost effectiveness of cholinesterase inhibitors in the treatment of Alzheimer's disease: a review with methodological considerations. Drugs Aging 2004;21:279-95.

30. Mesterton J, Wimo A, By A, Langworth S, Winblad B, Jonsson L. Cross-sectional observational study on the societal costs of Alzheimer's disease. Curr Alzheimer Res 2010;7:358-67.

31. Wilkinson D, Sganga A, Stave C, O'Connell B. Implications of the Facing Dementia Survey for health care professionals across Europe. Int J Clin Pract Suppl 2005;27-31.

32. Weaver J, Espinoza R, Weintraub N. The utility of PET brain imaging in the initial evaluation of dementia. J Am Med Dir Assoc 2007;8:150-7.

33. Christensen DD, Lin P. Practical treatment strategies for patients with Alzheimer's disease. J Fam Pract 2007;56:S17-23.

34. Bamford C, Eccles M, Steen N, Robinson L. Can primary care record review facilitate earlier diagnosis of dementia? Fam Pract 2007;24:108-16.

35. Ramakers IH, Visser PJ, Aalten P, et al. Symptoms of preclinical dementia in general practice up to five years before dementia diagnosis. Dement Geriatr Cogn Disord 2007;24:300-6.

36. Johnson DK, Wilkins CH, Morris JC. Accelerated weight loss may precede diagnosis in Alzheimer disease. Arch Neurol 2006;63:1312-7.

37. Buchman AS, Schneider JA, Leurgans S, Bennett DA. Physical frailty in older persons is associated with Alzheimer disease pathology. Neurology 2008; 71:499-504.

38. Galvin JE, Powlishta KK, Wilkins K, et al. Predictors of preclinical Alzheimer disease and dementia: a clinicopathologic study. Arch Neurol 2005;62:758-65.

39. Borson S, Scanlan JM, Watanabe J, Tu SP, Lessig M. Simplifying detection of cognitive impairment: comparison of the Mini-Cog and Mini-Mental State 
Examination in a multiethnic sample. J Am Geriatr Soc 2005;53:871-4.

40. Borson S, Scanlan J, Brush M, Vitaliano P, Dokmak A. The mini-cog: a cognitive 'vital signs' measure for dementia screening in multi-lingual elderly. Int J Geriatr Psychiatry 2000;15:1021-7.

41. Borson S, Scanlan JM, Watanabe J, Tu SP, Lessig M. Improving identification of cognitive impairment in primary care. Int J Geriatr Psychiatry 2006;21:349-55.

42. Borson S, Scanlan JM, Chen P, Ganguli M. The Mini$\mathrm{Cog}$ as a screen for dementia: validation in a populationbased sample. J Am Geriatr Soc 2003;51:1451-4.

43. Ismail Z, Rajji TK, Shulman KI. Brief cognitive screening instruments: an update. Int J Geriatr Psychiatry 2010;25:111-20.

44. Galvin JE, Roe CM, Coats MA, Morris JC. Patient's rating of cognitive ability: using the $\mathrm{AD} 8$, a brief informant interview, as a self-rating tool to detect dementia. Arch Neurol 2007;64:725-30.

45. Galvin JE, Fagan AM, Holtzman DM, Mintun MA, Morris JC. Relationship of dementia screening tests with biomarkers of Alzheimer's disease. Brain 2010; 133:3290-300.

46. Borson S, Scanlan J, Hummel J, Gibbs K, Lessig M, Zuhr E. Implementing routine cognitive screening of older adults in primary care: process and impact on physician behavior. J Gen Intern Med 2007;22:811-7.

47. Holmes SB, Adler D. Dementia care: critical interactions among primary care physicians, patients and caregivers. Prim Care 2005;32:671-82, vi.

48. Lawton MP, Brody EM. Assessment of older people: self-maintaining and instrumental activities of daily living. Gerontologist 1969;9:179-86.

49. Barberger-Gateau P, Commenges D, Gagnon M, Letenneur L, Sauvel C, Dartigues JF. Instrumental activities of daily living as a screening tool for cognitive impairment and dementia in elderly community dwellers. J Am Geriatr Soc 1992;40:1129-34.

50. Fitz AG, Teri L. Depression, cognition, and functional ability in patients with Alzheimer's disease. J Am Geriatr Soc 1994;42:186-91.

51. Monllau A, Pena-Casanova J, Blesa R, et al. [Diagnostic value and functional correlations of the ADAS-Cog scale in Alzheimer's disease: data on NORMACODEM project]. Neurologia 2007;22: 493-501.

52. Park KW, Pavlik VN, Rountree SD, Darby EJ, Doody RS. Is functional decline necessary for a diagnosis of Alzheimer's disease? Dement Geriatr Cogn Disord 2007;24:375-9.

53. Juva K, Makela M, Erkinjuntti T, et al. Functional assessment scales in detecting dementia. Age Ageing 1997;26:393-400.
54. Craig D, Mirakhur A, Hart DJ, McIlroy SP, Passmore AP. A cross-sectional study of neuropsychiatric symptoms in 435 patients with Alzheimer's disease. Am J Geriatr Psychiatry 2005;13:460-8.

55. Steffens DC, Maytan M, Helms MJ, Plassman BL. Prevalence and clinical correlates of neuropsychiatric symptoms in dementia. Am J Alzheimers Dis Other Demen 2005;20:367-73.

56. Lyketsos CG, Lee HB. Diagnosis and treatment of depression in Alzheimer's disease. A practical update for the clinician. Dement Geriatr Cogn Disord 2004; 17:55-64.

57. Kaufer DI, Cummings JL, Ketchel P, et al. Validation of the NPI-Q, a brief clinical form of the Neuropsychiatric Inventory. J Neuropsychiatry Clin Neurosci 2000;12:233-9.

58. Reisberg B, Borenstein J, Salob SP, Ferris SH, Franssen E, Georgotas A. Behavioral symptoms in Alzheimer's disease: phenomenology and treatment. J Clin Psychiatry 1987;48(Suppl):9-15.

59. Family Caregiver Alliance. Caregiver assessment: principles, guidelines and strategies for change. Report from a National Consensus Development Conference. Vol. 1. San Francisco: Family Caregiver Alliance; 2006.

60. Bultman DC, Svarstad BL. Effects of physician communication style on client medication beliefs and adherence with antidepressant treatment. Patient Educ Couns 2000;40:173-85.

61. Doody RS, Stevens JC, Beck C, et al. Practice parameter: management of dementia (an evidencebased review). Report of the Quality Standards Subcommittee of the American Academy of Neurology. Neurology 2001;56:1154-66.

62. Lyketsos CG, Colenda CC, Beck C, et al. Position statement of the American Association for Geriatric Psychiatry regarding principles of care for patients with dementia resulting from Alzheimer disease. Am J Geriatr Psychiatry 2006;14:561-72.

63. Galvin JE, Roe CM, Powlishta KK, et al. The AD8: a brief informant interview to detect dementia. Neurology 2005;65:559-64.

64. Pfeffer RI, Kurosaki TT, Harrah CH Jr, Chance JM, Filos S. Measurement of functional activities in older adults in the community. J Gerontol 1982;37:323-9.

65. Luchsinger JA, Mayeux R. Cardiovascular risk factors and Alzheimer's disease. Curr Atheroscler Rep 2004;6:261-6.

66. Dunn N, Mullee M, Perry VH, Holmes C. Association between dementia and infectious disease: evidence from a case-control study. Alzheimer Dis Assoc Disord 2005;19:91-4.

67. Scanlan JM, Binkin N, Michieletto F, Lessig M, Zuhr E, Borson S. Cognitive impairment, chronic disease burden, and functional disability: a population study of older Italians. Am J Geriatr Psychiatry 2007;15:716-24. 
68. Nasreddine ZS, Phillips NA, Bedirian V, et al. The Montreal Cognitive Assessment, MoCA: a brief screening tool for mild cognitive impairment. J Am Geriatr Soc 2005;53:695-9.

69. Folsom DP, Gilmer T, Barrio C, et al. A longitudinal study of the use of mental health services by persons with serious mental illness: do Spanishspeaking Latinos differ from English-speaking Latinos and Caucasians? Am J Psychiatry 2007;164: 1173-80.

70. Teng EL, Manly JJ. Neuropsychological testing: helpful or harmful? Alzheimer Dis Assoc Disord 2005;19:267-71.

71. Luis CA, Keegan AP, Mullan M. Cross validation of the Montreal Cognitive Assessment in community dwelling older adults residing in the Southeastern US. Int J Geriatr Psychiatry 2009;24:197-201.

\section{Appendix 1}

\section{The Mini-Cog Test}

Scoring: 1 point for each recalled word (Figure 1).

Score the clock drawing test (CDT) as normal (the patient places the correct time and the clock appears grossly normal) or abnormal.

\section{CDT Instructions}

A pen/pencil and a blank sheet of paper are required.

1. Instruct the patient to listen carefully and repeat the following:

Figure 1. The Mini-Cog Scoring Algorithm. $0=$ Positive for cognitive impairment; 1 or 2 plus an abnormal clock drawing test $($ CDT $)=$ positive for cognitive impairment; 1 or 2 plus a normal CDT = negative for cognitive impairment; $3=$ Negative screen for dementia (no need to score CDT). Reproduced with permission from Borson $S$ et al. Int $\mathbf{J}$ Geriatr Psychiatry 2000;15:1021-1027. (C) 2000 John Wiley \& Sons ${ }^{39}$

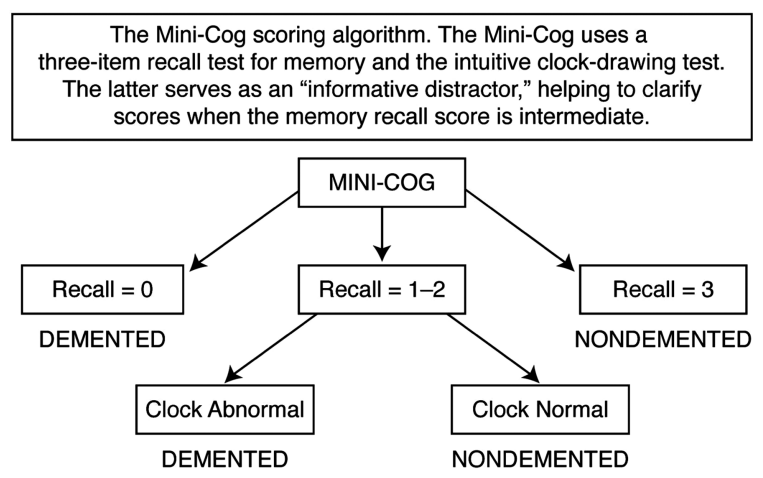

- Apple

- Watch

- Penny

2. Administer the CDT: ask the patient to draw a traditional clock face showing a time that is potentially confusing for someone with $\mathrm{AD}$, such as "10 minutes past 11."

3. Ask the patient to repeat the 3 words given previously.

Scoring (number of correct items recalled):

$3=$ Negative screen

1 or 2 plus normal CDT $=$ Negative screen

1 or 2 plus abnormal CDT $=$ Positive for $\operatorname{cog}$ nitive impairment

\section{Appendix 2}

\section{The AD8 Administration and Scoring Guidelines}

A spontaneous self-correction is allowed for all responses without counting as an error.

The questions are given to the respondent on a clipboard for self-administration or can be read aloud to the respondent either in person or over the phone (Table 3). It is preferable to administer the $\mathrm{AD} 8$ to an informant, if available. If an informant is not available, the AD8 may be administered to the patient.

- When administered to an informant, specifically ask the respondent to rate change in the patient

- When administered to the patient, specifically ask the patient to rate changes in his or her ability for each of the items without attributing causality

If read aloud to the respondent, it is important for the clinician to read the phrase carefully as worded and give emphasis to note changes caused by cognitive problems (not physical problems). There should be a 1-second delay between individual items.

- No time frame for change is required

- The final score is a sum of the number items marked "yes, a change"

\section{Interpretation of the $A D 8^{63}$}

A screening test in itself is insufficient to diagnose a dementing disorder. The AD8 is, however, quite sensitive to detecting early cognitive changes asso- 
1. Problems with judgment (eg, problems making decisions, bad financial decisions, problems with thinking)

2. Less interest in hobbies/activities

3. Repeats the same things over and over (questions, stories, or statements)

4. Trouble learning how to use a tool, appliance, or gadget (eg, VCR, computer, microwave, remote control)

5 . Forgets correct month or year

6. Trouble handling complicated financial affairs (eg, balancing checkbook, income taxes, paying bills)

7. Trouble remembering appointments

8. Daily problems with thinking, memory, or both TOTAL AD8 SCORE

*"Yes, a change" indicates that there has been a change in the last several years caused by cognitive (thinking and memory) problems. Scores of 0 to 1 indicate normal cognition; scores of $\geq 2$ indicate that cognitive impairment is likely to be present.

AD8, 8-item Ascertain Dementia screening.

Adapted with permission from Galvin J et al. Neurology 2006;67:1942-8. () 2006 AAN Enterprises, Inc. ${ }^{63}$

ciated with many common dementing illnesses including $\mathrm{AD}$, vascular dementia, Lewy body dementia, and frontotemporal dementia.

- Scores in the impaired range (see below) indicate a need for further assessment.

- Scores in the "normal" range suggest that a dementing disorder is unlikely, but an early disease process cannot be ruled out.

More advanced assessment may be warranted in cases where other objective evidence of impairment exists.

\section{The following cut points are used to diagnose dementia:}

- 0 or 1: Normal cognition

- $\geq 2$ : Cognitive impairment is likely to be present

\section{Appendix 3}

\section{Instrumental Activities of Daily Living ${ }^{13}$}

This tool evaluates the patient's ability to perform the more complex activities that are neces- sary for optimal independent functioning (Table 4). The scoring indicates whether the patient is completely independent (I), requires assistance (A), or is dependent (D) for the performance of each activity. The IADL instrument may be repeated periodically to determine the need for more support.

\section{Appendix 4}

Functional Assessment Questionnaire (FAQ) ${ }^{64}$

The FAQ includes 10 items and has been developed from the IADL scale (Table 5). The total score ranges from 0 (independent) to 30 (dependent).

\section{Appendix 5}

Neuropsychiatric Inventory Questionnaire ${ }^{13}$

The Neuropsychiatric Inventory Questionnaire provides a reliable assessment of behaviors frequently observed in patients with dementia. (Figure 2). 


\section{Table 4. Instrumental Activities of Daily Living Scale}

Name of patient. . . . . . . . . . . . . . . . . . . . . . . . . . . . . . . . . . . . . . . . . .

This form may help you assess the functional capabilities of your older patients. The data can be collected by a nurse from the patient or from an informant such as a family member or other caregiver (I = independent; $\mathrm{A}=$ assistance required; $\mathrm{D}=$ dependent $)$

\begin{tabular}{|c|c|c|c|}
\hline \multicolumn{2}{|c|}{ Obtained from } & \multirow[b]{2}{*}{ Activity } & \multirow[b]{2}{*}{ Guidelines for assessment } \\
\hline Patient & Informant & & \\
\hline \multirow[t]{3}{*}{ I A D } & IA D & Using telephone & $\mathrm{I}=$ Able to look up numbers, dial telephone, and receive and make calls without help \\
\hline & & & $\begin{array}{l}\text { A = Able to answer telephone or dial operator in an emergency, but needs special } \\
\text { telephone or help in getting numbers and/or dialing }\end{array}$ \\
\hline & & & $\mathrm{D}=$ Unable to use telephone \\
\hline \multirow[t]{3}{*}{ I A D } & I A D & Traveling & $\mathrm{I}=$ Able to drive own car or travel alone on buses or in taxis \\
\hline & & & $\mathrm{A}=$ Able to travel, but needs someone to travel with \\
\hline & & & $\mathrm{D}=$ Unable to travel \\
\hline \multirow[t]{3}{*}{ I A D } & I A D & Shopping & $\mathrm{I}=$ Able to take care of all food and all clothes shopping with transportation provided \\
\hline & & & A $=$ Able to shop, but needs someone to shop with \\
\hline & & & $\mathrm{D}=$ Unable to shop \\
\hline \multirow[t]{3}{*}{ I A D } & I A D & Preparing meals & $\mathrm{I}=$ Able to plan and cook full meals \\
\hline & & & $\mathrm{A}=$ Able to prepare light foods, but unable to cook full meals alone \\
\hline & & & $\mathrm{D}=$ Unable to prepare any meals \\
\hline \multirow[t]{3}{*}{ I A D } & I A D & Housework & $\mathrm{I}=$ Able to do heavy housework (i.e. scrub floors) \\
\hline & & & $\mathrm{A}=$ Able to do light housework, but needs help with heavy tasks \\
\hline & & & $\mathrm{D}=$ Unable to do any housework \\
\hline \multirow[t]{3}{*}{ I A D } & I A D & Taking medicine & $\mathrm{I}=$ Able to prepare and take medications in the right dose at the right time \\
\hline & & & $\mathrm{A}=$ Able to take medications, but needs reminding or someone to prepare them \\
\hline & & & $\mathrm{D}=$ Unable to take medications \\
\hline \multirow[t]{3}{*}{ I A D } & I A D & Managing money & $\mathrm{I}=$ Able to manage buying needs (i.e. write checks, pay bills) \\
\hline & & & $\begin{array}{l}\mathrm{A}=\text { Able to manage daily buying needs, but needs help managing checkbook and/or } \\
\text { paying bills }\end{array}$ \\
\hline & & & $\mathrm{D}=$ Unable to handle money \\
\hline
\end{tabular}

Adapted with permission from: Lawton MP, Brody EM. Gerontologist 1969;9:179-86. 1969 @ The Gerontological Society of America.

Table 5. Functional Assessment Questionnaire

\begin{tabular}{|c|c|c|c|c|c|}
\hline $\begin{array}{l}\text { In the Past } 4 \text { Weeks, Did the Subject Have Any } \\
\text { Difficulty or Need Help With: }\end{array}$ & $\begin{array}{l}\text { Not } \\
\text { Applicable }\end{array}$ & Normal & $\begin{array}{l}\text { Has Difficulty, } \\
\text { But Does by Self }\end{array}$ & $\begin{array}{l}\text { Requires } \\
\text { Assistance }\end{array}$ & Dependent \\
\hline 1. Writing checks, paying bills or balancing a checkbook & $\square$ & $\square$ & $\square$ & $\square$ & $\square$ \\
\hline $\begin{array}{l}\text { 2. Assembling tax records, business affairs, or other } \\
\text { papers }\end{array}$ & $\square$ & $\square$ & $\square$ & $\square$ & $\square$ \\
\hline $\begin{array}{l}\text { 3. Shopping alone for clothes, household necessities, or } \\
\text { groceries }\end{array}$ & $\square$ & $\square$ & $\square$ & $\square$ & $\square$ \\
\hline $\begin{array}{l}\text { 4. Playing a game of skill such as bridge or chess, } \\
\text { working on a hobby }\end{array}$ & $\square$ & $\square$ & $\square$ & $\square$ & $\square$ \\
\hline $\begin{array}{l}\text { 5. Heating water, making a cup of coffee, turning off } \\
\text { the stove }\end{array}$ & $\square$ & $\square$ & $\square$ & $\square$ & $\square$ \\
\hline 6. Preparing a balanced meal & $\square$ & $\square$ & $\square$ & $\square$ & $\square$ \\
\hline 7. Keeping track of current events & $\square$ & $\square$ & $\square$ & $\square$ & $\square$ \\
\hline $\begin{array}{l}\text { 8. Paying attention to and understanding a TV program, } \\
\text { book, or magazine }\end{array}$ & $\square$ & $\square$ & $\square$ & $\square$ & $\square$ \\
\hline $\begin{array}{l}\text { 9. Remembering appointments, family occasions, } \\
\text { holidays, medications }\end{array}$ & $\square$ & $\square$ & $\square$ & $\square$ & $\square$ \\
\hline $\begin{array}{l}\text { 10. Traveling out of the neighborhood, driving, or } \\
\text { arranging to take public transportation }\end{array}$ & $\square$ & $\square$ & $\square$ & $\square$ & $\square$ \\
\hline
\end{tabular}

Adapted from Pfeffer RI, Kurosaki TT, Harrah CH Jr, Chance JM, Filos S. Measurement of functional activities in older adults in the community. J Gerontol 1982;37:323-9. 1982 (C) The Gerontological Society of America. 
Figure 2. Neuropsychiatric Inventory Questionnaire ${ }^{13}$

Name of patient:

Date:

Informant: Spouse: Child: Other-

Please answer the following questions based on changes that have occurred since the patient first began to experience memory problems. Circle "yes" only if the symptom has been present in the past month. Otherwise, circle "no".

For each item marked "yes":

Rate the severity of the symptom (how it affects the patient):

1 = Mild (noticeable, but not a significant change)

2 = Moderate (significant, but not a dramatic change)

Rate the distress you experience because of that symptom (how it affects you):

$3=$ Severe (very marked or prominent; a dramatic change)

$$
\begin{aligned}
& 0=\text { Not distressing at all } \\
& 1=\text { Minimal (slightly distressing, not a problem to cope with) } \\
& 2=\text { Mild (not very distressing, generally easy to cope with) } \\
& 3=\text { Moderate (fairly distressing, not always easy to cope with) } \\
& 4=\text { Severe (very distressing, difficult to cope with) } \\
& 5=\text { Extreme or very severe (extremely distressing, unable to cope with) }
\end{aligned}
$$

Please answer each question honestly and carefully. Ask for assistance if you are not sure how to answer any question.

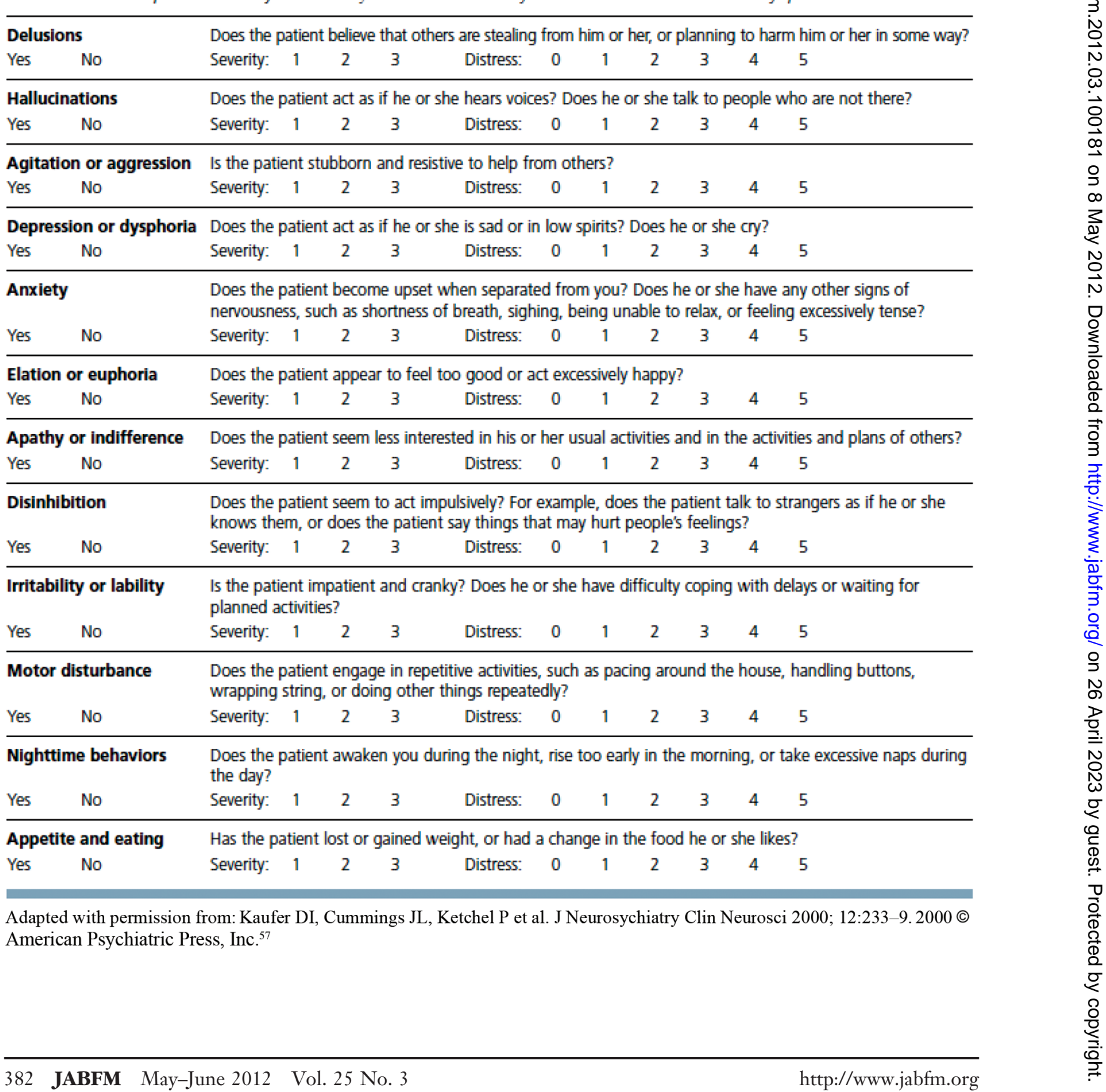

